\title{
Rheological Properties and Stability of Dermatocosmetic Emulsions with Collagen and Natural Ingredients Used as Color Correcting Cream and Cream Foundation
}

\author{
ELENA DANILA ${ }^{1,2}$, DURMUS ALPASLAN KAYA ${ }^{3}$, MIHAELA VIOLETA GHICA4*, MADALINA GEORGIANA ALBU KAYA ${ }^{1}$, \\ CRISTINA NEGREA ${ }^{2}$, LACRAMIOARA POPA ${ }^{4}$, CORNELIA NITIPIR ${ }^{5}$ \\ ${ }^{1}$ INCDTP -Division Leather and Footwear Research Institute, Collagen Department, 93 Ion Minulescu Str., 031215, Bucharest, \\ Romania \\ 2University Politehnica of Bucharest, Faculty of Applied Chemistry and Materials Science, 1-7 Gheorghe Polizu Str., 011061, \\ Bucharest, Romania \\ ${ }^{3}$ Mustafa Kemal University, Faculty of Agriculture, Department of Medicinal and Aromatic Plants, 31034, Antakya-Hatay, Turkey \\ ${ }^{4}$ Carol Davila University of Medicine and Pharmacy, Faculty of Pharmacy, Department of Physical and Colloidal Chemistry, \\ 6 Traian Vuia Str., 020956, Bucharest, Romania \\ ${ }^{5}$ Carol Davila University of Medicine and Pharmacy, Faculty of Medicine, 8 Eroilor Sanitari Blvd, 050513, Bucharest, Romania
}

The aim of this study was to formulate and evaluate two types of O/W emulsions based on collagen and other natural ingredients that can be used as color correcting (CC-cream) and cream foundation. Both types of emulsions obtained are stable at different temperatures and the $\mathrm{pH}$ values of emulsions correspond to the natural $\mathrm{pH}$ of the skin, indicating that emulsions can be safely applied to the skin. Results from the optical microscopy analysis show that all emulsions present foam-like appearance. The rheological properties of emulsions were studied and it was proved that all emulsions present a non-Newtonian pseudoplastic behaviour and thixotropic characteristics at two operating temperatures $\left(24\right.$ and $\left.33^{\circ} \mathrm{C}\right)$. It can be concluded that all emulsions can be used as a natural alternative to a CC-cream or a cream foundation. Further microbiological tests and clinical trials are necessary for the obtained emulsions.

Keywords: collagen, CC-cream, cream foundation, rheological behaviour

Emulsions are defined as disperse systems consisting of two immiscible liquids which are stabilized by the addition of an emulsifying agent, called emulsifier (also known as emulgent) [1]. Two liquids can form different types of emulsions: oil and water can form, firstly, an oil-inwater emulsion $(\mathrm{O} / \mathrm{W})$, wherein the oil is the dispersed phase and water is the dispersion medium and secondly, they can form a water-in-oil emulsion (W/0), wherein water is the dispersed phase and oil is the external phase. Multiple emulsions are also possible, including a water-in-oil-inwater (W/O/W) emulsion and an oil-in-water-in-oil (O/W/ $0)$ emulsion [2]. Due to their applications in medicine and cosmetics the formulation of $\mathrm{O} / \mathrm{W}$ emulsions gained recently an increased interest in scientific papers [3].

Skin care cosmetics and emulsions are closely related. The recent emulsion technology has advanced the quality of cosmetics [4].Additional value can be conferred to these formulations by including active ingredients with specific cosmetic effects [5]. Particularly advantageous cosmetic emulsion preparations are obtained when natural proteins are used as active ingredients. Collagen is one of the natural proteins used in cosmetic preparations due to its biodegradability, availability and biocompatibility [6]. Collagen is the most abundant protein of the human body, is naturally present in the connective tissues and makes the dermis resistant, supple and elastic. In particular, it is an effective natural humectant as result of the extensive, ordered hydration network that surrounds the molecule, in combination with its high substantivity to the skin surface [7].

In the last years the interest in the pharmaceutical and cosmetic industry to use plant extracts for various fields of application was substantially growing, due to the adverse effects generated by synthetic ingredients [8]. Essential oils have been used to improve the health and physical appearance of the human body, and to protect the skin against the environment damage since ancient times [9]. Essential oils are complex mixtures containing dozens of substances of various chemical composition at different concentrations [10]. They are characterized by the compounds present in highest concentration which determine their flavour, fragrance and biological properties [11]. Biological proprieties of essential oils such as antibacterial, antifungal and antioxidant activity make essential oils suitable for use in cosmetics [12, 13].

Trends in the field of cosmetics target cosmeceuticals products which are hybrid products, intended to enhance the beauty through ingredients that provide additional health-related functions or benefits [14]. Dermatocosmetics, performance cosmetics, functional cosmetics, dermaceuticals, active cosmetics and nutricosmetics are other terms used for cosmeceuticals [15]. Decorative cosmetics represent an important sector of cosmetics industry that adopted this trend [16]. Make-up products are no longer used just for decorative purposes but also for terapeutical properties. In this respect, cream foundation represent a good example, which become a dermatocosmetic product, that not only have the ability to camouflage small skin imperfections but also have beneficial properties on skin such as moisture, sunscreen, and moreover is noncomedogenic and does not irritate skin compared to conventional products [17]. RecentlyCCcream (color control or color correcting) and BB-cream (blemish balm or beauty balm) were developed, which are multitasking products correcting visible skin 
imperfections, like a foundation, and also add other benefits by treating the skin like a traditional cream product [18].

Considering these aspects, the aim of this study was to prepare O/W emulsions, usable as CC-cream and cream foundation, based on naturals ingredients such as vegetable oils and butters, hydrolyzed collagen and essential oils, and to evaluate the rheological properties of these emulsions.

\section{Experimental part}

Materials and methods

Collagen hydrolysate was obtained byacid hydrolysis of wet white leather wastes at $125^{\circ} \mathrm{C}$ during $8 \mathrm{~h}$ according to the technology previously described [19].

The essential oils, lavender (Lavandula angustifolia), rosmarinus (Rosmarinus officinalis), cistus (Cistus ladaniferus) and pinus (Pinus sylvestris), were obtained in Department of Medicinal and Aromatic Plants, Faculty of Agriculture, Mustafa Kemal University, Hatay, Turkey from wild plants from the province of Hatay in the period of their blooming.

Vegetable oils (almond oil, rice oil, avocado oil), mango butter, emulsifiers (glyceryl stearate, cetearyl olivate, sorbitan olivate), mineral pigments brown, yellow and pearly beige (iron oxides: $\mathrm{Cl} 77491, \mathrm{Cl} 77492, \mathrm{Cl} 77499, \mathrm{Cl}$ 77019, $\mathrm{Cl} 77891$ ), floral waters (chamomile and lavender), glycerin, xanthan gum, rice powder, panthenol, preservative cosgard (benzyl alcohol, salicylic acid, glycerin, sorbic acid) and titanium oxide were purchased from https://www.elemental.eu/ro/.

\section{Formulation of $\mathrm{O} / \mathrm{W}$ emulsions}

The chemical composition for both types of emulsions, CC-cream (color correcting cream) and cream foundation, is presented in table 1.

The ingredients of phase $A$ and phase $B$ are heated in a water bath in two heat-resistant Berzelius beakers, periodically homogenizing the composition. When both phases reach a temperature of about $70-75^{\circ} \mathrm{C}$, they are removed from the water bath; then, the content of phase $B$ is slowly added over phase $A$ by mixing constantly. The mixing continued for a few minutes, avoiding as much as possible the aeration of the emulsion. The ingredients from phase $\mathrm{C}$ were then added to the composition and mixed for a few minutes. The beaker was placed in a cold water glass and the composition was continuously stirred. In the cooled composition, the ingredients of phase $\mathrm{D}$ are added and mixed slowly. The obtained emulsion is transferred to a sterile container.

\section{Characterization of O/W emulsion}

Physical characterization, stability and $\mathrm{pH}$

For the obtained emulsions the organoleptic (color, appearance, smell) and physical (phase separation) properties were optically observed. $\mathrm{pH}$ was evaluated using a inoLab pH meter. For all obtained emulsions, stability tests were performed at different temperatures: room temperature $\left(20-23^{\circ} \mathrm{C}\right), 4-5^{\circ} \mathrm{C}$ (refrigerator) and $40^{\circ} \mathrm{C}$ (incubator).

Optical microscopy analysis was performed using a LEICA optical microscope model S8AP0, with Increase Power: 20-160x.

Rheological analysis was performed with a rotational viscometer Multi Visc-Rheometer (Fungilab) equipped with a TR 10 standard spindle and a ThermoHaake P5 Ultrathermostat to maintain constant the sample temperature during the measurements. The operational conditions were detailed in our previous studies [20]. The creams flow ability was determined at 24 and $33^{\circ} \mathrm{C}$. For each cream a rotational speed over the range from 0.3 to $60 \mathrm{rpm}$ was applied at both temperatures, corresponding to a shear rate between $0.08-16.8 \mathrm{~s}^{-1}$. The rheological data were fitted according to Power law model expressed as viscosity as a function of shear rate (eq. 1):

$$
\eta=\mathrm{m} \cdot \dot{\gamma}^{-\mathrm{n}}
$$

where, $m$ and $n$ are parameters correlated with the formulation factors of the designed creams and determined by linearization of eq. (1) by double logarithmic method [21]. It can be appreciated that the value of $m$ parameter corresponds to the viscosity obtained for the shear rate value of $1 \cdot \mathrm{s}^{-1}$. To assess the thixotropic behaviour of the cosmetic cream stested, the up- and down-curves shear stress as a function of shear rate were built.

The thixotropic character was quantified by two parameters [22].

1) Thixotropy area $\left(S_{\text {thix }}\right)$ defined as the area between the up-and down-curve. The up-curve represents the area bounded by the ascending curve (Sasc) and is associated with the manipulation time of the cosmetic product when it is exposed to the skin. The down-curve corresponds to

\begin{tabular}{|c|c|c|c|c|c|}
\hline \multirow[b]{2}{*}{ Phase } & \multirow[b]{2}{*}{ Ingredients } & \multicolumn{2}{|c|}{ CC-cream } & \multicolumn{2}{|c|}{ Cream foundation } \\
\hline & & $T$ & 2 & 1 & 2 \\
\hline A & almond oil, $\mathrm{mL}$ & 20 & 15 & - & - \\
\hline$A$ & mango butter, g & 10 & 15 & 15 & - \\
\hline A & titanium oxide, g & - & - & 5 & 5 \\
\hline A & rice oil, $\mathrm{mL}$ & - & - & 15 & 20 \\
\hline A & avocado oil, $\mathrm{mL}$ & - & - & - & 10 \\
\hline $\mathbf{A}$ & emulsifier ${ }^{*}, g$ & 5 & 5 & 6 & 6 \\
\hline$A$ & brown pigment, $g$ & 0.1 & 0.05 & 0.02 & 0.1 \\
\hline $\mathbf{A}$ & yellow pigment, $g$ & 0.5 & 0.1 & 0.05 & 0.5 \\
\hline A & pearly beige pigment, $g$ & - & - & 0.05 & 1 \\
\hline B & chamomile water, $\mathrm{mL}$ & 60 & 60 & - & - \\
\hline B & lavender water, $\mathrm{mL}$ & - & - & 56 & 55 \\
\hline B & glycerine, $\mathrm{mL}$ & 1 & 1 & - & - \\
\hline B & collagen, g & 1.15 & 1.6 & 1.23 & 1.25 \\
\hline $\mathrm{C}$ & xanthan gum, g & 0.2 & 0.2 & 0.1 & 0.1 \\
\hline $\mathrm{C}$ & rice powder, $g$ & 0.5 & 0.5 & - & - \\
\hline $\mathrm{C}$ & panthenol, $\mathrm{mL}$ & 1 & 1 & 1 & 1 \\
\hline D & cosgard preservative, $\mathrm{mL}$ & 0.5 & 0.5 & 0.5 & 0.5 \\
\hline D & essential oil, $\mathrm{mL}^{* *}$ & 0.05 & 0.05 & 0.05 & 0.05 \\
\hline
\end{tabular}

Table 1

CHEMICAL COMPOSITION OF CC-CREAM AND CREAM FOUNDATION

CC-cream: glyceryl stearate; cream foundation: cetearyl olivate, sorbitan olivate

\&* CC-cream: 1-rosmarinus, 2-lavender; cream foundation: 1-cistus, 2-pinus. 
the descending area $\left(\mathrm{S}_{\text {decs }}\right)$ and it refers to the restoration of the initial structure of the shear formulation.

2) Thixotropy index $\left(T_{\text {hysto }}\right)$ represents the relative thixotropy area and is computed as a percentage of the rheodistruction area caused by agitation at the maximum rotational speed, reported to the ascending area (eq. 2). Thixotropic systems are those with $\mathrm{T}_{\text {hyst } \%}$ values greater than $5 \%$

$$
\mathrm{T}_{\text {hyst } \%}=\left(\frac{\mathrm{S}_{\text {asc }}-\mathrm{S}_{\text {desc }}}{\mathrm{S}_{\text {asc }}}\right) \cdot 100
$$

\section{Results and discussions}

\section{Physical characterization, stability and $\mathrm{pH}$}

The emulsions obtained are homogeneous and present different colors, as shown in figure 1, depending on the quantity of pigments used.

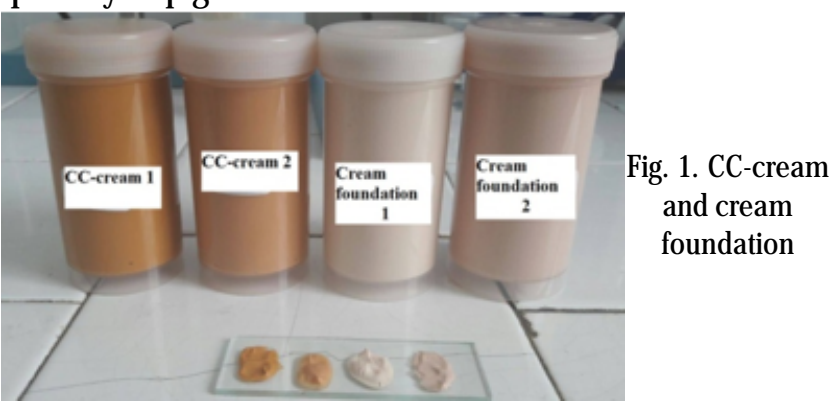

All emulsions have a pleasant, creamy, moisturized appearance and a smell specific to the essential oils in the composition. No phase separation was observed shortly after preparation. On the skin the CC-creams present a light coverage, while the cream foundation present a medium coverage due to titanium oxide and the combination of the three pigments used. Titanium oxide also adds sun protection factor (SPF) to the cream foundation formulations.

Following the stability tests, all emulsions were found to be stable at all three working temperatures.

The $\mathrm{pH}$ values of the obtained emulsions are shown in table 2.

Table 2

THE $p H$ VALUES FOR THE OBTAINED EMULSIONS

\begin{tabular}{|c|c|c|c|c|}
\hline & $\begin{array}{c}\text { CC- } \\
\text { cream 1 }\end{array}$ & $\begin{array}{c}\text { CC- } \\
\text { cream 2 }\end{array}$ & $\begin{array}{c}\text { Cream } \\
\text { foundationl }\end{array}$ & $\begin{array}{c}\text { Cream } \\
\text { foundation2 }\end{array}$ \\
\hline $\mathrm{pH}$ & 6.4 & 6 & 6.1 & 6.5 \\
\hline
\end{tabular}

The natural $p \mathrm{H}$ of the skin varies between $4.5-6.5$ and this interval is considered to be optimal for cosmetic products that are indirectcontact with the skin [5]. The values obtained for the emulsions are in this interval, indicating thatemulsions can be safely applied on the skin.

\section{Optical microscopy analysis results are presented in figures 2 and 3.}

From the optical microscopy images, it can be seen that all emulsions have foam-like appearance, even if slightly aerated in the case of cream foundation due to the titanium oxide form the composition. The size of the pigments incorporated in emulsions is of hundreds of micrometers (200-500um), due to the fact that during the process of production, heat tend to form aggregates of the primary pigment particles which are then closely attached and become very difficult to separate [23].

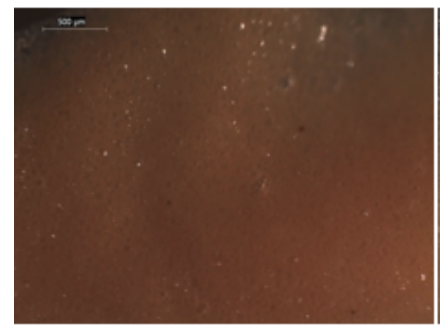

a)

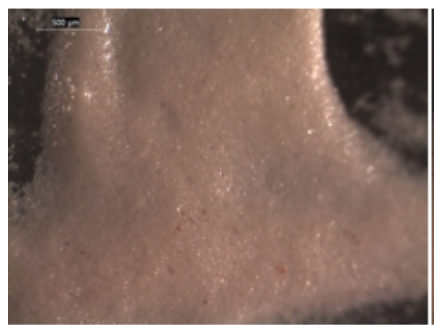

c)

Fig. 2. Optical microscopy images of CC-cream (a,b) and cream foundation $(c, d)$

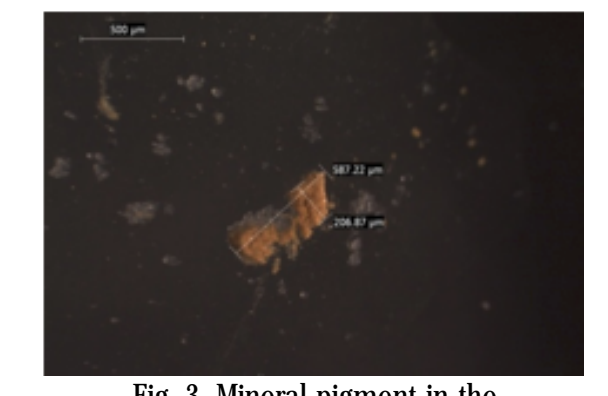

Fig. 3. Mineral pigment in the compositions of CC-cream 1 b)

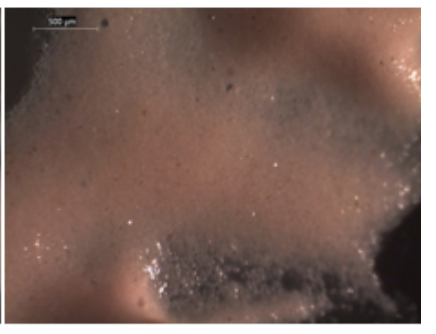

d)
Rheological analysis

Pseudoplastic behaviour

The results of the rheological experiments obtained at two operating temperatures $\left(24\right.$ and $\left.33^{\circ} \mathrm{C}\right)$ for the designed cosmetic emulsions, are presented in figure 4a-b.

From figure $4 a-b$ the influence of the composition on the viscosity of the formulations tested at both operating temperatures can be noticed. Thus, the CC-cream 1 is more viscous than the CC-cream 2 , respectively the cream foundation 1 has a higher viscosity compared to the cream foundation 2.

The rheological patterns recorded in figure $4 a-b$ also show the influence of the temperature on the tested emulsions viscosity, which decreases with temperature increase due to the fluidization of the system.

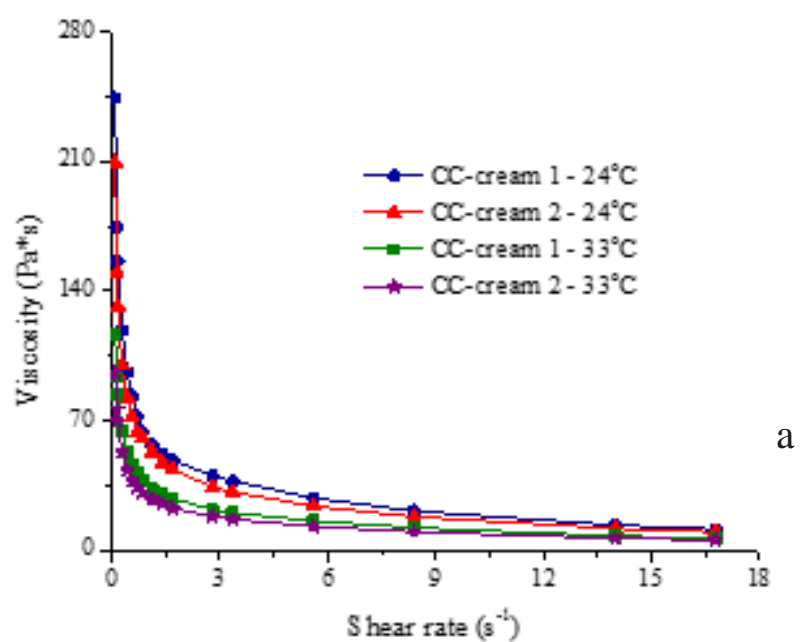

Fig. 4. Plots of viscosity as a function of shear rate corresponding to:a) CC-creams 


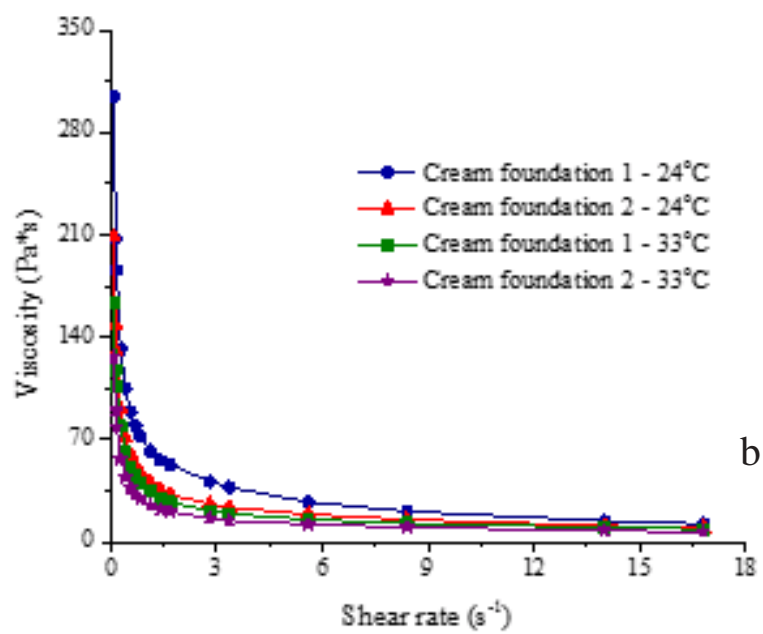

Fig. 4. Plots of viscosity as a function of shear rate corresponding to b) cream foundations analyzed at $24^{\circ} \mathrm{C}$ and $33^{\circ} \mathrm{C}$

All rheograms show that the viscosity of the tested systems decrease with shear rate increaseat both operating temperatures, indicating a pseudoplastic nonNewtonian behaviour with shear thinning of the emulsions.

For the quantification of the pseudoplastic behaviour, the Power law rheological model that express the relationship between viscosity and shear rate was applied (eq. 1). The values of the rheological parameters, $m$ and $n$, and the determination coefficient $R^{2}$ specific to the above model are listed in table 3 for the formulations tested at $24^{\circ} \mathrm{C}$ and in Table 4 for the formulations analyzedat $33^{\circ} \mathrm{C}$, respectively.

For the formulations tested, values of determination coefficient $R^{2}$ between 0.9953 and 0.9992 are recorded, indicating that the experimental data verify this rheological model.

Table 3

THE VALUES OF THE RHEOLOGICAL PARAMETERS MAND $n$ AND THE DETERMINATION COEFFICIENT $\mathrm{R}^{2}$ SPECIFIC TO THE POWER LAW MODEL APPLIED TO THE EMULSIONS ANALYZED AT $24^{\circ} \mathrm{C}$

\begin{tabular}{|c|c|c|c|}
\hline Emulsion & $\mathbf{~}$ & $\mathbf{n}$ & $\mathbf{R}^{\mathbf{2}}$ \\
\hline CC-cream l & 61.142 & 0.537 & 0.9966 \\
\hline CC-cream 2 & 53.811 & 0.524 & 0.9953 \\
\hline Cream foundation 1 & 64.530 & 0.601 & 0.9959 \\
\hline Cream foundation 2 & 43.107 & 0.618 & 0.9974 \\
\hline
\end{tabular}

Table 4

THE VALUES OF THE RHEOLOGICAL PARAMETERS $m$ AND $n$ AND THE DETERMINATION COEFFICIENT R² SPECIFIC TO THE POWER LAW MODEL APPLIED TO THE EMULSIONS ANALYZED AT $33^{\circ} \mathrm{C}$

\begin{tabular}{|c|c|c|c|}
\hline Emulsion & $\mathbf{m}$ & $\mathbf{n}$ & $\mathbf{R}^{2}$ \\
\hline CC-cream 1 & 35.401 & 0.478 & 0.9984 \\
\hline CC-cream 2 & 28.986 & 0.479 & 0.9988 \\
\hline Cream foundation 1 & 37.279 & 0.582 & 0.9992 \\
\hline Cream foundation 2 & 26.974 & 0.604 & 0.9972 \\
\hline
\end{tabular}

For the emulsions analyzed at the two operating temperatures, it is observed that atincreasing temperature the rheological parameter $m$ recorded a decrease of about 1.60-1.85 times.

For CC-cream 1 a value of the parameter $m$ higher than 1.13 times is recorded compared to CC-cream 2 tested at $24^{\circ} \mathrm{C}$, and 1.22 times higher at $33^{\circ} \mathrm{C}$.

For the cream foundation 1 , a value of the parameter $m$ 1.49 times higher is recorded compared to the cream foundation 2 tested at $24^{\circ} \mathrm{C}$, and 1.38 times higher at the temperature of $33^{\circ} \mathrm{C}$.

\section{Thixotropic behaviour}

The study of thixotropic behaviour is achieved by obtaining the rheorgam corresponding to the up-curve (ascending curve) at increasing shear rate, and down-curve (descending curve) recorded at decreasing shear rate. For the same shear rate, the points on the return curves correspond to shear stresses lower than those on the upcurves. The thixotropy phenomenon is characteristic to plastic and pseudoplastic flow dispersion systems [22].

The up-and down-curves shear stress as a function of shear rateare illustrated in figures 5 and 6 for the formulations analyzed at 24 and $33^{\circ} \mathrm{C}$.

The rheograms presented in figures 5 and 6 show that all the tested formulations have a thixotropic character at both temperatures, the descending curve being placed under the ascending curve.
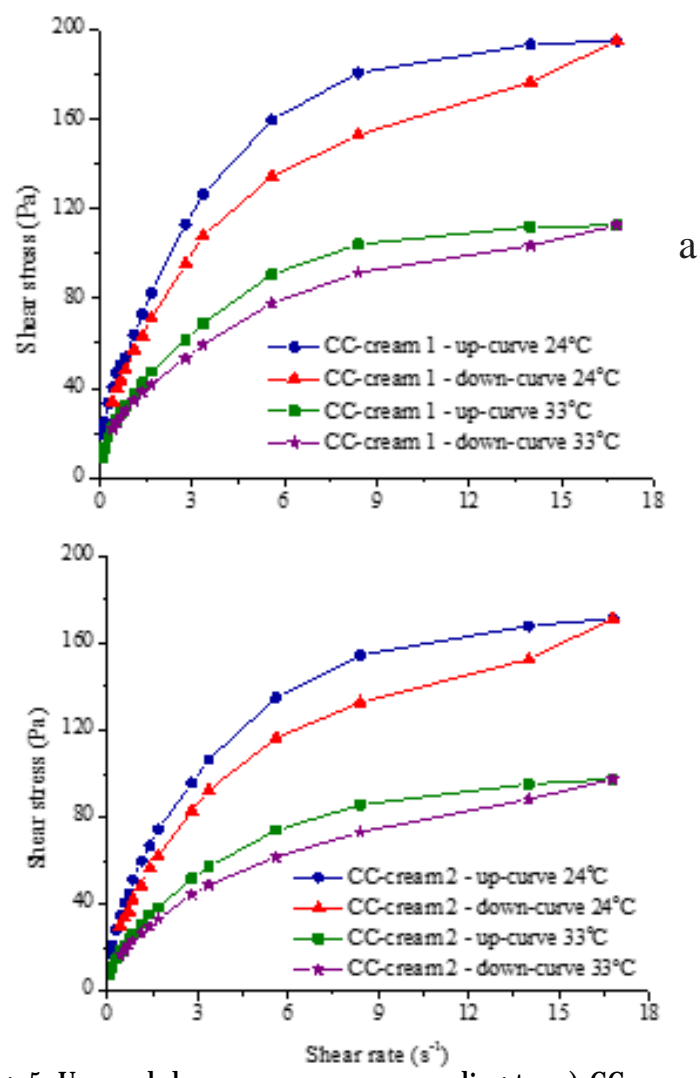

Fig. 5. Up- and down-curves corresponding to: a) CC-cream 1; b) CC-cream 2 analized at $24^{\circ} \mathrm{C}$ and $33^{\circ} \mathrm{C}$

Tabel 5

THE THIXOTROPIC PARAMETER VALUES DETERMINED FOR THE EMULSIONS ANALYZED AT $24^{\circ} \mathrm{C}$

\begin{tabular}{|c|c|c|c|c|}
\hline Emulsion & $\begin{array}{c}\mathrm{S}_{\mathrm{asc}} \\
\left({\left.\mathrm{Pa} \cdot \mathrm{s}^{-1}\right)}^{-1}\right)\end{array}$ & $\begin{array}{c}\mathrm{S}_{\text {desc }} \\
\left({\left.\mathrm{Pa} \cdot \mathrm{s}^{-1}\right)}^{-1}\right)\end{array}$ & $\begin{array}{c}\mathrm{S}_{\mathrm{tix}} \\
\left(\mathrm{Pa} \cdot \mathrm{s}^{-1}\right)\end{array}$ & $\begin{array}{l}T_{\text {hyst9s }} \\
(\%)\end{array}$ \\
\hline CC-cream 1 & 2651.182 & 2333.290 & 317.892 & 11.99 \\
\hline CC-cream 2 & 2285.766 & 2024.327 & 261.439 & 11.43 \\
\hline $\begin{array}{c}\text { Cream foundation } \\
1\end{array}$ & 2677.723 & 2341.49 & 336.233 & 12.55 \\
\hline $\begin{array}{l}\text { Cream foundation } \\
2\end{array}$ & 1946.314 & 1732.568 & 213.746 & 10.98 \\
\hline
\end{tabular}



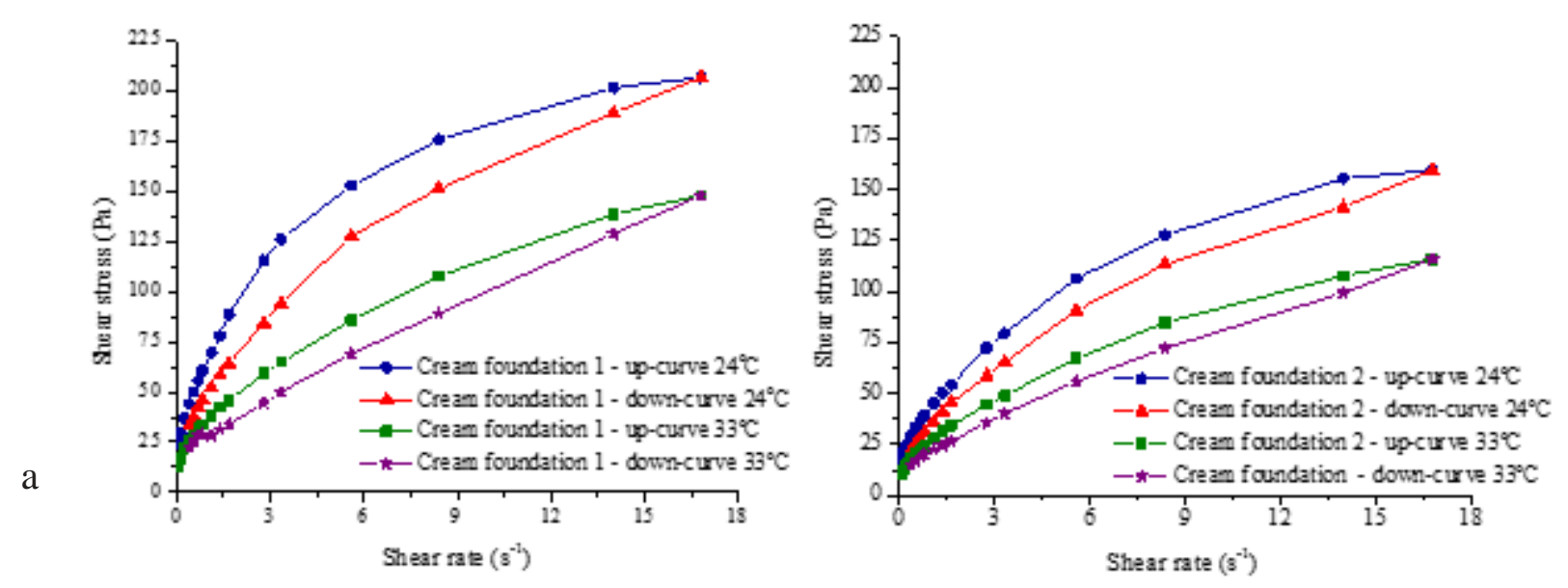

Fig. 6. Up- and down-curves corresponding to: a) Cream foundation 1; b) Cream foundation 2 analized at $24^{\circ} \mathrm{C}$ and $33^{\circ} \mathrm{C}$

Tabel 6

THE THIXOTROPIC PARAMETER VALUES DETERMINED FOR THE EMULSIONS ANALYZED AT $33^{\circ} \mathrm{C}$

\begin{tabular}{|c|c|c|c|c|}
\hline Emulsion & $\begin{array}{c}\mathrm{S}_{\text {asc }} \\
\left(\mathbf{P a}^{-1}\right)\end{array}$ & $\begin{array}{c}\mathrm{S}_{\text {desc }} \\
\left(\mathbf{P a}^{-1} \mathbf{s}^{-1}\right)\end{array}$ & $\begin{array}{c}\mathbf{S}_{\text {tix }} \\
\left(\mathbf{P a}^{-1}\right)\end{array}$ & $\begin{array}{c}\mathbf{T}_{\text {hyst9s }} \\
(\%)\end{array}$ \\
\hline CC-cream 1 & 1519.846 & 1366.200 & 153.646 & 10.10 \\
\hline CC-cream 2 & 1269.034 & 1125.046 & 143.988 & 11.34 \\
\hline $\begin{array}{c}\text { Cream foundation } \\
\mathbf{1}\end{array}$ & 1675.783 & 1458.230 & 217.553 & 12.98 \\
\hline $\begin{array}{c}\text { Cream foundation } \\
\mathbf{2}\end{array}$ & 1305.270 & 1153.036 & 152.234 & 11.67 \\
\hline
\end{tabular}

The values corresponding to the ascending area, descending area, thixotropy area and thixotropy index are givenin tables 5 and 6 for the formulations analyzed at 24 and $33^{\circ} \mathrm{C}$.

The values of the thixotropy index listed in tables 5 and 6 are superior to $5 \%$, indicating that the designed cosmetic formulations are thixotropic at both operating temperatures. It is noted that the increase of temperature decreases the values recorded for ascending, descending and thixotropy areas.

\section{Conclusions}

Both types of emulsions (CC-cream and cream foundation) obtained are stable at different temperatures and the value obtained for the $\mathrm{pH}$ of the emulsions correspond to the natural $\mathrm{pH}$ of the skin, indicating that emulsions can be safely applied to the skin.

Results of the optical microscopy analysis shows that all emulsions have foam-like appearance and the cream foundation is slightly aerated.

The emulsions tested present a pseudoplastic nonNewtonian behaviour with shear thinning atboth operating temperatures. The pseudoplastic behaviour of the designed cosmetic formulations was quantified through the rheological model of the Power law - viscosity as a function of shear rate.

Pseudoplastic behaviour is a desirable requirement for systems with topical application both in terms of conditioning and spread on the skin and the formation of a continuous film at the application site. At high shearing speeds, such as when dispensing from the conditioning vessel, the material will flow rapidly by facilitating administration, while at low shear rates, such as the product being spread on the skin, the material will adopta high consistency by recovering the original rheological properties possessed before administration.

Thixotropic analysis was performed using specific descriptors such as thixotropic area and thixotropy index.
The thixotropic nature is also a quality parameter sought in order to convert an initially viscous emulsion in a thin product, easy to spread on the skin.

Both flow parameters and thixotropy characteristics determined are strongly influenced by the composition of the cosmetic formulations and the operating temperature.

It can be concluded that all the emulsions prepared are stable, safe for the skin and present adequate rheological properties, so it can be used as a natural alternative for a CC-cream or a cream foundation. In the future microbiological tests and clinical trials are necessary for the obtained emulsions.

Acknowledgements: The authors acknowledge the financial support from the project PN 163402 07/2016.

\section{References}

1.MADAAN,V., CHANANA, A., KUMAR KATARIA,M., BILANDIA., Int. Res. J. Pharm., 5, no.7, 2014, p. 533.

2. YAQOOB KHAN, A., TALEGAONKAR, S., IQBAL, Z., JALEES AHMED, F., KRISHAN KHAR R., Curr. Drug. Deliv., 3, no. 4 , 2006, p. 429.

3. ANGHELACHE, A. M., KIM, L., CUCIUREANU A., BATRINESCU G., PASCU, L. F., Rev. Chim. (Bucharest), 68, no. 8, 2017, p. 1681.

4. SAKAl, Y., Int. J. Cosmet. Sci., 27, no. 2, 2005, p. 133.

5. SMAOUI, S., HLIMA, H. B., JARRAYA R., GRATI KAMOUN, N., ELLOUZE, R., DAMAK, M., Afr. J. Biotechnol., 11, p. 40, 2012, p. 9664.

6. BINTI ABD SAMAD, N. A., SINGH SIKARWAR A., Int. J. Biochem. Res. Rev., 14, no. 3, 2016, p.1.

7. PENG, Y., GLATTAUER, V., WERKMEISTER, J. A., RAMSHAW, J . A.M., J. Cosmet. Sci., 55, 2004, p.327.

8. STANCIU, G., CHIRILA, E., DOBRINAS. S., NEGREANU-PIRJOL, T., Rev. Chim.(Bucharest) , 61, no. 1, 2010, 41.

9. SHAABAN, H.A.E., EL-GHORAB, A.H., SHIBAMOTO, T., J., Essent. Oil Res., 24, 2012, p. 203.

10. DO, T., HADJ I-MINAGLOU, F., ANTONIOTTI, S. AND FERNANDEZ, X., Trends Anal. Chem., 66, 2015, 146. 
11. CARVALHO, I. T., ESTEVINHO, B. N., SANTOS, L., Int. J. Cosmet. Sci., 38, 2016, 109.

12. RAUT, J.S., KARUPPAYIL, S.M. A, Ind. Crops Prod. 62, 2014, 250.

13. M. DREGER, WIELGUS, K., Herba Polonica, 59, no. 4, 2013.

14. WANJARI, N., WAGHMARE, J., Int. J. Pharm. Res. Rev., 4, no. 5, 2015, p. 45.

15. SHARMA, P., Int. J. Pharm. Tech., 3, no.4, 2011, p. 1512.

16. ABDULLAH, B. J., NASREEN R., Int. J. Pharm. Tech., 4, no. 1, 2012, p.3925.

17.*** https://www.avene-me.com/en_MO/makeup/correct-and-unifythe-complexion/fluid-foundation-correctors

18. BALDECCHI, T., ZUR LAGE, J., BAI, R., WU, S., ZHUANG, J., WITTE, G., PFLUCKER, F., Int. J. Appl. Sci., 138, 2012, p.1.
19. TRANDAFIR V., POPESCU G., ALBU M. G., IOVU H., GEORGESCU M., Collagen-based Bioproducts (in Romanian), Ars Docendi, Bucharest, 2007, 111-112.

20. GHICA, M.V., ALBU, M.G.,. DINU-PIRVU, C., MOISESCU, S., Rev. Chim.(Bucharest), 63, no. 9, 2012, p. 929.

21. KAYA, D.A., SAYIN, S., FERDES, M., ALBU, M.G., UNAL, N., TURKMEN, M., OZTURK, S., CONSTANTINESCU, R.R, GHICA, M.V., Proc. 5th Int. Conf. Adv. Mater. Syst., October 23-25, 2014, Bucharest, p. 237.

22. GHICA, M.V., HIRJAU, M., LUPULEASA, D., DINU-PIRVU, C., Molecules, 21, no. 6, 2016.

23. THIEMANN, A., GRONE, S., SALMINA-PETERSEN, M., JANICHEN, J ., Int. J.Appl. Sci., 141, no.9, 2015, p. 34.

Manuscript received: 15.07 .2018 